\title{
Informal Care Regimes: The Case of Rural Greece
}

\author{
Ekaterini Ntaflou ${ }^{1,2}$ \\ ${ }^{1}$ Local Government, Social Policy and Information and Communication Technologies, Athens, Greece \\ ${ }^{2}$ Panteion University of Social and Political Sciences, Athens, Greece \\ Email: katentaf@yahoo.gr
}

How to cite this paper: Ntaflou, E. (2021) Informal Care Regimes: The Case of Rural Greece. Open Journal of Social Sciences, 9, 352-363.

https://doi.org/10.4236/jss.2021.91026

Received: December 22, 2020

Accepted: January 23, 2021

Published: January 26, 2021

Copyright $\odot 2021$ by author(s) and Scientific Research Publishing Inc. This work is licensed under the Creative Commons Attribution International License (CC BY 4.0).

http://creativecommons.org/licenses/by/4.0/ (c) (i) Open Access

\begin{abstract}
Society's gradual ageing has significantly affected the need for improvement of the care services for the elderly and the people with disabilities. This study aims to understand mechanisms of informal provision of services, the facilitators, and barriers for such practices on this adaptive mechanism in rural areas in Greece. The baseline of this article is a field study that was conducted in villages of two remote municipalities of Greece. The article comparatively analyses in the place of residence differences as a factor of conformation of a unique care and support regime that is offered to the elderly and disabled people. The article identifies regional patterns and explores implications for resident's ability to access social welfare and the health market. The article contributes by incorporating the special characteristics of place of residence in the analysis of informal welfare regimes.
\end{abstract}

\section{Keywords}

Elderly, Disabled, Regimes, Reinforcement, Local Community, Informal Care Regimes

\section{Introduction}

The ageing of society is leading to significant reforms in long-term care policy and systems in many European countries. The ever-growing ageing of the population makes the Greek healthcare system as the most European healthcare systems operate based on the demand for long-term healthcare services. This drives these systems to financial problems, especially, during periods of abatement of state benefits and other fiscal downscales. The interest in the need for long-term care (LTC) for the ever-growing number of the vulnerable population (elderly and disabled) has encouraged the search for solutions. Solutions that will make the 
financial sustainability of the care system possible and they will also create a better balance between offer and demand of care. This raises the question as to whether the volume of informal care will increase in the years ahead.

This question is even more pertinent in the light of a widely acceptable argument concerning the informal care regimes is that informal care is an element (Hoffmann \& Rodrigues, 2010; Broese van Groenou \& De Boer, 2016), an often invisible "pillar" of our welfare systems (Boll et al., 2018) that is formed by the social background of each country (Polese et al., 2014; Hrzenjak, 2012). This mainly happens as the "perceivable duty" for care varies among countries (Naiditch et al., 2013).

Drawing on the definition of Kröger and Yeandle (2013: p. 13), by "informal" or "family" carers, we refer to "someone providing care based in a relational, affective or neighbourly context to a person with care needs arising from disability, long-term or terminal illness, or frailty in old age". The informal care model starts with the notion that someone in the social network is in need of care. To what degree the care provided depends on several factors (care recipient, caregivers). As such, the provision of informal care is depicted as a process in which factors of both care recipient and caregiver are intertwined (Colombo et al., 2011).

The concept of informality nevertheless is not new in Social Policy. On the contrary, it represents an important element of Social Policy and of the equivalent informal welfare policies. Quite often, it has to do with the main (informal) care that people in need receive and it is comprised of state-based and residual family-based systems. In spite of the unavoidable different perception of the term of informality by both those who are responsible for the creation of policies and those who belong in academia, there is a wider and more discerning prospect that sees informal cares as adjuvant, interdependent with the formal process of care that is mainly considered as family's responsibility and continues within the local community.

Based on this background, Townsend's theory connects the informal Social Policy to the overall (in)effectiveness and legality of the state. As noted by Townsend (Townsend, 1979), the term "culture of informality" further undermines the state's ability to provide effective public services. This is partly related to the residual social welfare approach of the state.

\section{Problem Statement}

In Greece, since the 70's, public policies and programs promoted a sense of greater responsiveness that was coming from informal regimes and, mostly, from the families members. Many of these features relate to different measures or dimensions of informality and indeed, are reflections of a systemic failure.

Among those features, we have

- low coverage of many social insurance schemes.

- low-quality regulation that increases bureaucracy. 
- low-quality public provision of many social services (such as health care or education).

- low levels of trust in the state.

The establishment of a general framework for the analysis of the informal social protection networks of the rural population of Greece is reflected in the identification of mainly two main concerns. These include: addressing the social service needs of vulnerable populations and how vulnerable populations adapt to the needs and difficulties of accessing social services.

Realizing that there are objective and subjective factors which determine welfare access, the analysis argues that the organizational structure of society and the mentalities and values associated with it reflect the gaps of the official state.

The scientific analysis of the objective difficulties of access to goods and social protection services to a certain extent in Greece was followed by a macro-structural approach (Petmesidou \& Mosialos 2006). The interest was focused on the studies of Getimis and Petrinioti (2003), and Psimmenos (2009) on the deficit on benefits but also on informal practices. From the scientific findings of the above studies, what basically emerges is that access to social goods and services is determined by two important dimensions of social protection. These include: living and working conditions (demographic and social characteristics, habits, values and expectations) and service conditions.

These different concepts about informal care are connected to concepts of value and the ethics of each country as well as the financial background of the welfare state and the degree of the generosity of the provided benefits. According to studies, these benefits affect the "structure of care" which varies among the different regimes of social care and among countries which have different types of a welfare state (Kaschowitz \& Brandt, 2017; Frericks et al., 2014; Larsen, 2005; Serrano-Pascual, 2007). In this sense, the financial parameter forces the informal care regimes and, mainly, the family members (family) to deal with the biggest part of the care that is required for the vulnerable population (Brandt, 2013).

According to European studies (Courtin et al., 2014; Rutherford \& Bu, 2017) depending on the country, the informal care may be provided by: 1) adults who care for their family members, neighbors or friends, 2) pensioners who care for their family members, neighbors or friends, 3) paid non-professional carers who replace or complement the care that is provided by the family. Informal care regimes belong mainly to the immediate environment of the elderly and disabled people. They manage the coverage of their daily health and care needs which could potentially restrict the independence of elderly and disabled people and their ability to stay healthy and socially active.

\section{Objective of the Study}

The main objective of this study was to examine the significant of informal care regimes in isolated and mountainous areas which are characterized by the low population, the disarticulation of the fabric of society and, therefore, of the fam- 
ily itself, and the problems of accessibility.

\section{Significance of the Study}

To improve on the capability of health care systems and local government rural information and knowledge about social support with local agencies-mainly informal and voluntarily - has to be utilized by local government and health care managers. Hence, this study determined their present level of access to and utilization of agricultural information and knowledge and examined the socio-economic advancements, the structure and the duration of the social services that transfer the care from the official bodies to the community and to the personal care are particularly important. It identified the needs of the elderly and disabled people who live in remote and inaccessible rural areas and the constraints they face to meet their needs and reduce their problems. It also determined the characteristics and the effect of the informal regimes in attainment of goals that concern each person, especially those who face difficulties due to their physical debilities.

\section{Hypotheses}

The following hypotheses were tested:

$\mathrm{H}_{1}$ : Significant relationship exists between the informal care regimes offer services on a frequent and emergency basis to the elderly and disabled members and the rural and isolated villages.

$\mathrm{H}_{2}$ : Significant relationship exists between the necessity and usefulness of these informal regimes for the disabled and/or elderly population and the geophysical characteristics of the place of residence.

$\mathrm{H}_{3}$ : Significant relationship exists between the daily and emergency response to the needs of the elderly and disable, and the external kind of help to them. Informal care regimes have specific characteristics.

\section{Methodology}

\section{Study area}

The study was carried out in the region of Epirus in Greece. Epirus is one of the 13 administrative, geographical and financial regions of Greece. It is a rugged and mountainous region and it is considered to be the poorest region of Europe. The Region of Epirus is divided into 4 Regional Units (R.E.) and 18 Municipalities. The region often has low temperature throughout the year and heavy rainfall. The climate is cold and humid, influenced by rain-bearing winds from the central Europe. The rainy and snow covered season lasts from September to April. According to the criterion of the density of population of OECD, Epirus Region represents a region, a rural area with immense (many times extreme) negative characteristics and an equally high need for services.

The most important problems regard the low income, unfavorable demographic composition, low educational level and lack of basic infrastructure (National Stra- 
tegic Rural Development Plan (NSRDP), 2007-2013). The main issue is the decline of the population inhabiting these areas. The decline of population is not a new phenomenon. On the contrary, various factors were added over the years, such as the migration from the rural areas, the ageing of the population, the unemployment in agriculture, the difficult living conditions, the availability of services (e.g. public, social), the poverty and low incomes, the decreasing agricultural domain, the environmental issues (climate change and the weather phenomena that are connected to it, biodiversity), the size of local markets (KarcagiKovats \& Katonane-Kovacs, 2012).

However, the particularity in this case is that this rural area is characterized by a significant percentage of elderly people who live permanently, all their lives or after their retirement, in a small or big village. These are mainly people who have a series of health and living problems due to their age or their general physical condition. Many of them live on their own. The conditions in the Greek countryside are particularly demanding for the fulfillment of their basic needs, especially in the remote and inaccessible mountainous villages. The access of the elderly and disabled population to a series of goods and services of the modern civilization is quite often difficult due to the distance and isolation and/or the physical or financial difficulties.

\section{Sampling Technique and Size}

The study used multistage sampling technique. In the first stage, two (2) Local Government Areas (LGAs) namely: Municipality of Central Tzoumerka and Municipality of Dodoni out of the 18 Municipalities in Epirus were purposively selected based on the high percentages of ageing, in a very under populated environment (Table 1, Table 2).

Secondly, ten communities from each LGA were randomly selected. Thus, a total of twenty (20) communities were selected for the study. Snow balling technique was used to collect the data. Data for this study was collected from primary and secondary sources. The primary data was obtained through a mix qualitative research interviews and quantitative research. For the needs of the project, a

Table 1. Data of dynamic rise of elderly people in municipalities of R.U. of Epirus (2011).

\begin{tabular}{cccccc}
\hline \multirow{2}{*}{$\begin{array}{c}\text { Regions } \\
\text { of Epirus (4 regions) }\end{array}$} & $\begin{array}{c}\text { Total of } \\
\text { population }\end{array}$ & $\boldsymbol{\Sigma}$. [0 - 64] & $\%[\mathbf{0}-\mathbf{6 4}]$ & $\boldsymbol{\Sigma}$. [65+] & \% [65+] \\
\cline { 2 - 6 } R. Epirus & 336.856 & 257.874 & 76.55 & 78.982 & 23.45 \\
R.U. Ioannina & 167.901 & 131.492 & 78.32 & 36.409 & 21.68 \\
M. Dodoni & 9.693 & 5.928 & 61.16 & 3.765 & 38.84 \\
R. U. Arta & 67.877 & 49.455 & 72.86 & 18.422 & 27.14 \\
M. Tzoymerka & 6.178 & 3.211 & 51.97 & 2.967 & 48.03 \\
R. U. Thesprotia & 43.587 & 33.055 & 75.84 & 10.532 & 24.16 \\
R. U. Preveza & 57.491 & 43.872 & 76.31 & 13.619 & 23.69 \\
\hline
\end{tabular}

Source: ELSTAT. 2011 (last population census). 
Table 2. Rate of ageing \& population density of R.U. Arta and Ioannina.

\begin{tabular}{|c|c|c|c|c|c|}
\hline Study area & Municipality & $\begin{array}{l}\text { Mountainous } \\
\text { Lowland }\end{array}$ & $\begin{array}{l}\text { Population } \\
\text { density rate }\end{array}$ & $\begin{array}{c}\text { Ageing rate } \\
(135.4)\end{array}$ & $\begin{array}{l}\text { Average } \\
\text { altitude }\end{array}$ \\
\hline \multirow{3}{*}{ Arta } & $1.662 \mathrm{~km}^{2}$ & & 40.84 & 2.14 & \multirow{3}{*}{172} \\
\hline & $\begin{array}{c}\text { Municipality } \\
\text { of Arta }\end{array}$ & Mountainous & 94.40 & 1.55 & \\
\hline & $\begin{array}{l}\text { Municipality } \\
\text { of Tzoumerka }\end{array}$ & Mountainous & 12.13 & 7.56 & \\
\hline \multirow[b]{2}{*}{ Ioannina } & $4.990 \mathrm{~km}^{2}$ & & 33.64 & 1.65 & \multirow[b]{2}{*}{563} \\
\hline & $\begin{array}{c}\text { Municipality } \\
\text { of Dodoni }\end{array}$ & Lowland & 14.74 & 5.06 & \\
\hline
\end{tabular}

Source: ELSTAT. 2011 (last population census).

guide based on three subjects was developed (MacDonald \& Headlam, 2008). The first subject contained general information about the field of research (structures, local authorities, characteristics of the organizations, positive experiences, problems and obstacles) and policies. The second strand sought to provide an initial assessment (adequacy of resources and benefits, social impact of the intervention, its effects on the characteristics of social policies for the disabled and old residents, suggestions for future improvements).

The third subject contained qualitative research. Qualitative research is primarily exploratory research. The preselected criteria were relevant to particulars research questions as well as the study's objectives. Characteristics were included age, place of residence, gender, marital status, disability, etc. The criteria we choose allow us to focus on people we think would be most likely to experience, know about, or have insights into the research topic. In order to gain an understanding of underlying reasons, opinions, and motivations the interviews took place during the winter at homeplaces of the disabled and old residents. As no research interview lacks structure the qualitative research interviews were either lightly structured or in-depth. In order to have the interview data captured more effectively, recording of the interviews was an appropriate choice during the interviews. Some common methods include focus groups (small size group discussions), individual interviews. Four interviews were done with representatives at the local governmental levels, four interviews were with central-level officials (policy-makers and experts), another four with the municipal social service officers. Furthermore, one hundred fifty interviews were done with disabled and old residents both genders.

The analysis of the present research was conducted based on the hypothesis that the informal care regimes offer services to the elderly and disabled members of the rural and isolated villages on a frequent and emergency basis. That happens because, on one hand, there is no other alternative and, on the other, because they wish to do so and they are able to do it. This entails a certain age and financial and social status of the people who provide the service, an ability to deal/solve the matters that concern the elderly or disabled public. The necessity 
and usefulness of these informal regimes for the disabled and/or elderly population are connected to the danger of marginalisation and exclusion of these groups due to their personal characteristics (such as their age) and/or other specific elements, as well as general elements (geophysical characteristics of the place of residence). Furthermore, the administrative system's inability to cover the needs of this population is added to the above.

The secondary data was obtained from previous publications such as journals, internet, conference proceedings and relevant textbooks. Data collected was analyzed using descriptive statistics and inferential statistics. The Statistical Package for Social Sciences was used to analyze the data collected from the respondents.

\section{Results and Discussion}

\section{Perceived barriers to care}

\section{i. Materials and immaterial issues}

The study captured the difficulty of fulfillment of the needs of elderly and disabled people and the limitations that concern the accessibility to the healthcare structure in the rural area. The research showed that the possession and use of a vehicle helps immensely in the daily service. Nevertheless, the possession of a vehicle is not always connected to its use as this is independent from individual factors, both personal and external. The most significant ones have to do with the weather conditions, the distances between the place of residence and the place of service and the financial and physical situation of the respondent.

An elderly's or disabled's person stable physical and mental health is affected by many external factors and changes frequently due to the unsteadiness of the human environment around them. These factors are making the feeling of loneliness and isolation greater. This fact drives to significant physical and emotional dependency. As shown by the research, the solidarity-based relationships in the village and the neighborhood play a particularly important role. As they point out, their life would certainly be in danger and the hope for help does not exist: (One respondent noted that): "If I die, that's it, it's over... if I can make it out of my house and make a phone call, or else they might find me dead".

According to the elderly and disabled people, if or whenever they have a serious and life-threatening emergency, their survival and any medical help is "God's will". They say: (One respondent noted that): "the hospital can't come closer to us... we'll go and find it... by chance." This opinion is supported by the fact that their streets, especially in mountainous villages, are not always in good condition and it gets worse when the weather conditions are bad, especially during wintertime. Oftentimes, rocks, pieces of wood and big masses of dirt and water block the road and make transport impossible.

Any other means of transport (use of taxi) only occurs if there is the financial ability. The average cost of this service is very high compared to their pensions that most of the elderly people in the area receive (agriculture pension). Usually, just the transit to the town equals the $1 / 4$ or even $1 / 2$, of their pension and if the 
taxi needs to wait at the hospital for the return of the elderly or disabled person then it adds up. (One respondent noted that): “Taxi? It' ll cost 80 Euros just to get there, if you tell them that you want them to wait and take you back it's $200 \mathrm{Eu}$ ros".

The sentiments produced by the lack of or difficulty of fulfillment of these needs are connected to the nature-geography of the place of residence based on the research's sample. In essence, the place of residence determines the field of exclusion for the elderly and disabled people and, apart from their personal characteristics; it also has characteristics of geography, local development, and infrastructures.

\section{ii. Caregivers- "Informal Care Regimes"}

The daily and emergency response to the needs of the elderly and disable, in the villages where the research was conducted, is the problem and its solution depends on an external kind of help to them. This kind of help is informal, non-constituted and, therefore, not stable. It is usually someone who is going to help them with matters of transit to the doctor, the purchase of products or medicine, even the processing of formal documents. They comprise the category that, for the research, is called informal care regimes. The residents' offer to volunteer to the expressed need that comes with age and disability is what makes the difference between those who give it and those who need it. It's an expression of the community's ability that is based on individuals without a collective/official support. It expresses the process of strengthening the community and its vulnerable members as a three-stage sequence: (Chart 1).

As a term, "regime" does not refer to a group of people. It expresses the combination of actions and services that a person offers, ensuring the personal fulfillment of the vulnerable population as well as the cohesion and coherence of the community. According to the research, these informal regimes have a series of common characteristics that can be divided into two main categories:

a) Informal care regimes that are composed by people who live in the same village as the vulnerable population: According to the research, one can create the grouping of the main characteristics of the informal regimes in the Greek countryside in a chart. Furthermore, the fact that the informal care regimes are a special category of people with various extensions is proven: (Chart 2).

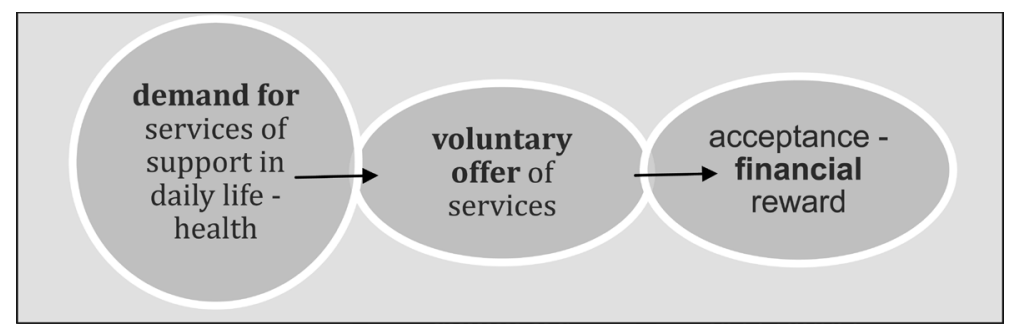

Source: Own edit.

Chart 1. The 3 stages of support of the vulnerable population. 


\begin{tabular}{|c|c|c}
\hline $\begin{array}{c}\text { Men, young, } \\
\text { Car owner }\end{array}$ & 2. Unemployed & Funded \\
2. Health or service Professional & Not funded & Volunteer \\
\hline
\end{tabular}

Source: Own edit

Chart 2. The informal care regimes.

1) These regimes could be composed by one or two people in every village. Contrary to most relevant studies (Schmidt et al., 2016; UNECE, 2018; Hoffmann \& Rodrigues, 2010), it is composed by men who live in the same village as the elderly and disabled people. 2) They have an array of personal traits such as age and education. They are usually 35 - 55 years old (in an elderly environment), unskilled workers or farmers. Due to their age or the nature of their job and their marital status (unwedded), they are considered "capable" or "available" to help the elderly and disabled population. 3) the main service that they provide to the disabled and elderly people have to do with shopping and/or transport that happens with their own vehicles for the daily shopping, processing of public sector matters and visit to the Health Clinic/Hospital and/or private doctor.

The care and support of the elderly and disable members of the family (mainly the women's of the family responsibility) is part of the Greek tradition (OECD, 2007; Liakou, 1998; Mpoursanidis, 2000). However, according to the study it is proven that the care/service for the elderly and disabled does not belong only to the category of values as the result of free will. In this case, volunteering has its limitations. It expresses, on some occasions, the difficulty of survival of young people in the mountainous and low-populated area (most of this population is unemployed) who offer their services either exclusively and/or additionally to their main jobs, sometimes charging a fee.

4) In the village environment, care is viewed as a "compulsory" and "constrained" service for both sides (the side of elderly-disabled and the side of the provider), due to the lack of other alternative solutions and the moral obligation to help.

b) Informal care regimes are comprised by people who work in certain professional categories of medical, paramedic and other public services. 1) The first professional category is the category of pharmacists. The pharmacist is the one who provides medicine and services concerning information, advice, and mental support. Usually, the elderly/disable people know their pharmacist personally, they order their medicine, and s/he sends them to their village, saving them from difficult and expensive transportation to and from the urban centre or the neighboring town where the pharmacy is located.

2) The interesting thing about this second category of informal carers is the participation of people from other professional categories without any evident relationship to them. The case of the postman is characteristic, especially in the mountainous villages of Dodoni Municipality. They transfer medicines and food to the elderly/disabled people. As the elderly-disabled people say: (One respondent noted that): "I order the medicine from the pharmacist 3 - 4 days in ad- 
vance and he sends them to me with the postman."

\section{Conclusion}

Despite being a qualitative study capturing the perspective of a small sample of informal care regimes, we believe that the importance of the findings of this study still reflect the current context of informal provision of services and its various challenges. Understanding whether informal care act as substitutes or complements is important. The informal care regimes are a parameter of an informal Social Service that acts independently in the place of residence reassuring the supply of care to the population in need. Currently, this population needing services will continue to grow.

As noted, informal care regimes are related to the underlying need for help and care. According to the informal model of care that was described, the relationship of the elderly/disabled person with their carers is a relationship that shows a one-sided dependency to the daily and emergency needs. It is a complicated process that depends on the personal needs of the elderly/disabled people and differs from municipality to municipality, from village to village and even from home to home. The medical, family and financial background of each elderly/disabled person determines both the degree of fulfillment of their needs from the regime and the need for formal or informal services. From the above analysis, it is established that three personal (micro-) variables (people, motives and need) are connected and interact with three collective macro-variables (place, availability of informal services and financial benefits) as components of health and living of the vulnerable population of the small rural local community. In the rural community, the support for daily life and health is not necessarily judged by the rules of "market economy" but mainly by "gift economy" (Mauss, 1999) in which the financial motives are active but not primary.

The understanding of these informal care regimes in the remote and inaccessible environments of the Greek countryside, firstly, shows the "social weight" of these areas that do not have alternative and/or enough mechanism/care services. Secondly, through the evaluation of emergencies in the areas where the research was conducted, additional material for useful deductions for the matter of accessibility to the healthcare infrastructures is provided. According to the article, accessibility is an indication of people's ability to overcome distances and physical obstacles in the road network. Furthermore, the same matter of accessibility concerns the efficiency of infrastructures, formal and informal, which should accommodate, facilitate and fulfill the needs that arise from the people-geography of their area of responsibility.

Besides, the centre of interest of the elderly and disabled people is the "support of needs" that arises in basic daily actions and emergencies. These needs are a constant convention and a dependent relationship. It concerns both the "subject" of acceptance of the practices for the balance of needs and the bodies of this action, the civic or informally offered services. Caring is a very important aspect 
in our society. This is because a lot of people are getting old and other groups of people need care. Informal caring has been found to be useful in helping people cope with problems of health and daily problems. For this reason, informal care is a social parameter that diminishes the uncertainty in an area filling the gaps of the formal infrastructure. Thus, intervening in the social networks of older adults or disabled can be an investment in population health, with manifold implications for health and public policy. However, to formulate policies, one should know the degree to which social networks influence health, which aspects of health are affected, and which groups should be targeted.

\section{Conflicts of Interest}

The author declares no conflicts of interest regarding the publication of this paper.

\section{References}

Boll, T. J., Ferring, D., \& Valsiner, J. (2018). Cultures of Care in Aging. Charlotte, NC: IAP, Information Age Publishing, Inc. https://www.worldcat.org/

Brandt, M. (2013). Intergenerational Help and Public Assistance in Europe. A Case of Specialization? European Societies, 15, 26-56.

https://doi.org/10.1080/14616696.2012.726733

Broese van Groenou, M. I., \& De Boer, A. (2016). Providing Informal Care in a Changing Society. European Journal of Ageing, 13, 271-279.

https://doi.org/10.1007/s10433-016-0370-7

Colombo, F. et al. (2011). Help Wanted? Providing and Paying for Long-Term Care. OECD Health Policy Studies, OECD Publishing. https://www.semanticscholar.org/paper/Help-wanted-\%3A-providing-and-paying-for-1 ong-term-Colombo/073c13f8e13d367efa2274b7d00bd9588d194934 https://doi.org/10.1787/9789264097759-en

Courtin, E., Jemiai, N., \& Mossialos, E. (2014). Mapping Support Policies for Informal Carers across the European Union. Health Policy, 118, 84-94. https://doi.org/10.1016/j.healthpol.2014.07.013

Frericks, P., Jensen, H., \& Pfau-Effinger, B. (2014). Social Rights and Employment Rights Related to Family Care: Family Care Regimes in Europe. Journal of Aging Studies, 29, 66-77. https://doi.org/10.1016/j.jaging.2013.12.002

Getimis, P., \& Petrinioti, X. (2003). Research to Address the Problems Faced by Public Officials in the Service of Immigrants-Returnees-Refugees. Final Report, Athens.

Hoffmann, F., \& Rodrigues, R. (2010). Informal Carers: Who Takes Care of Them? Policy Brief 4/2010, Vienna: European Centre.

Hrzenjak, M. (2012). Hierarchisation and Segmentation of Informal Care Markets in Slovenia. Social Politics: International Studies in Gender, State \& Society, 19, 38-57. https://doi.org/10.1093/sp/jxr024

Karcagi-Kovats, A., \& Katonane-Kovacs, J. (2012). Factors of Population Decline in Rural Areas and Answers Given in EU Member States' Strategies. Studies in Agricultural Economics, 114, 49-56. https://doi.org/10.7896/j.1105

Kaschowitz, J., \& Brandt, M. (2017). Health Effects of Informal Caregiving across Europe: A Longitudinal Approach. Social Science \& Medicine, 173, 72-80. 
https://doi.org/10.1016/j.socscimed.2016.11.036

Kröger T., \& Yeandle, S. (2013). Reconciling Work and Care: An International Analysis. In T. Kröger, \& S. Yeandle (Eds.), Combining Paid Work and Family Care. Policies and Experiences in International Perspective (pp. 3-22). Bristol: Policy Press. https://doi.org/10.2307/j.ctt9qgp6n.7

Larsen, J. E. (2005). The Active Society and Activation Policy: Ideologies, Contexts and Effects. In J. G. Andersen, A. M. Guillemard, P. Jensen, \& B. Pfau-Effinger (Eds.), The Changing Face of Welfare: Consequences and Outcomes from a Citizenship Perspective (pp. 135-159). Bristol: Policy Press.

Liakou, M. (1998). Home Help Hellenic Red Cross: Dimensions and Development Perspectives of Domiciliary Social Care. Social Work, 52, 203-209. (In Greek)

MacDonald, S., \& Headlam, N. (2008). Research Methods Handbook. Introductory Guide to Research Methods for Social Research. Manchester: Center for Local Economic Strategies.

Mauss, M. (1999). The Gift. Shapes and Functions of the Exchange. Athens: Kastaniotis Publications.

Naiditch, M., Triantafillou, J., Di Santo, P., Carretero, S., \& Hirsch Durrett, E. (2013). User Perspectives in Long-Term Care and the Role of Informal Carers. In K. Leichsenring, J. Billings, \& H. Nies (Eds.), Long-Term Care in Europe: Improving Policy and Practice (pp. 45-80). London: Palgrave Macmillan.

https://doi.org/10.1057/9781137032348 3

National Strategic Rural Development Plan (NSRDP) (2007-2013). Greece, Data Source FAO, FAOLEX. http://www.espa.gr

OECD (2007). The OECD Health Project-Long-Term Care for Older People. Paris: OECD. https://doi.org/10.1787/9789264065369-ko

Petmesidou, M., \& Mossialos, E. (2006). Addressing Social Protection and Policy in Greece. In M. Petmesidou, \& E. Mossialos (Eds.), Social Policy Developments in Greece (pp. 1-24). Farnham: Ashgate Publishing.

Polese, A., Morris, J., Kovács, B., \& Harboe, I. (2014). “Welfare States” and Social Policies in Eastern Europe and the Former USSR: Where Informality Fits in? Journal of Contemporary European Studies, 22, 184-198. https://doi.org/10.1080/14782804.2014.902368

Psimmenos, I. (2009). The Contribution of Domestic Work to the Welfare Marginalisation of Migrant Women. Social Cohesion and Development, 4, 139-154.

Rutherford, A., \& Bu, F. (2017). Issues with the Measurement of Informal Care in Social Surveys: Evidence from the English Longitudinal Study of Ageing. Ageing and Society, 38, 2541-2559. https://doi.org/10.1017/S0144686X17000757

Schmidt, A. E., Winkelmann, J., Rodrigues, R., \& Leichsenring, K. (2016). Lessons for Regulating Informal Markets and Implications for Quality Assurance-The Case of Migrant Care Workers in Austria. Ageing \& Society, 36, 741-763. https://doi.org/10.1017/S0144686X1500001X

Serrano-Pascual, A. (2007). Reshaping Welfare States and Activation Regimes. In A. Serrano-Pascual, \& L. Magnusson (Eds.), Reshaping Welfare States and Activation Regimes in Europe (pp. 11-35). Brussels, Belgium: P.I.E. Peter Lang.

Townsend, P. (1979). Poverty in the United Kingdom. Harmondsworth: Penguin.

UNECE (2018). Innovative Social Services and Supportive Measures for Independent Living in Advanced Age. UNECE Policy Brief on Ageing No. 20.

https://www.unece.org/fileadmin/DAM/pau/age/Policy briefs/ECE WG1 28.12.pdf 